\title{
Sacrificing the personal to the professional: community mental health nurses
}

Journal of Advanced Nursing, 42, (5): 527-538.

\section{Pamela Majomi}

Doctoral Research Student, Faculty of Health and Community Studies, De Montfort University, Leicester, UK

B. Brown

Faculty of Health and Community Studies, De Montfort University, Leicester, UK Paul Crawford

School of Nursing, Queens Medical Centre, University of Nottingham, Nottingham, UK Journal of Advanced Nursing 42(5), 527-538

\section{Abstract}

Background. The study of stress in mental health nurses has almost always focused on factors intrinsic to their job roles and has neglected the interaction between work and home roles, which may also be a source of stress. Moreover, role theory has not provided an adequate account of either personal or occupational change, especially when this results from the experience of stress. Methods. Twenty community mental health nurses agreed to participate in semi-structured interviews about the stresses they experienced at work and at home. A grounded theory analysis disclosed the centrality of conflicts between work and home roles in participants' accounts and this provided the focus for subsequent detailed readings of the interview transcripts.

Findings. Participants described how difficult and often demanding family situations were integrated with professional careers in a climate of rapid organizational change in the health service. As well as being an ongoing source of strain, these competing role demands were often described as leading to sudden changes for individual workers, such as periods of illness or re-evaluation of their work role. To assist in making sense of this process, the term 'punctuated equilibria' was adopted to illuminate the build-up of tension between work and domestic lives, which was described by some workers as leading to a sudden reformulation of their relationship to their work roles and employing organizations.

Conclusions and limitations. The study was small-scale and relied on retrospective self-reports. Nevertheless, it emphasized the importance of considering all the roles that individuals play and highlights the possibility that, even when staff are apparently coping with 
their roles at work and home, difficulties may be building up which could lead to a sudden period of absenteeism or disillusionment.

Keywords: community mental health nurses, stress, roles, home-work conflict

\section{What is already known about this topic}

Nursing is widely acknowledged to be stressful.

There is a good deal of interest in conflict between work roles and family roles, yet this issue has been neglected in nursing research.

What this paper adds

This paper explores the issue of home-work conflict though a series of interviews with community mental health nurses.

Home-work conflict was described as a major source of difficulty in participants' lives, and these difficulties were coped with in a kind of dynamic equilibrium.

Changes in participants' lives often occurred suddenly as a result of a moment of realization, and their narratives thus take the form of 'punctuated equlibria'.

\section{Introduction}

Research dealing with how community mental health nurses reconcile the competing demands of their professional and personal lives has been lacking. However, the growing body of work concerning other occupations suggests that there may be interconnecting and reciprocal influences between family and work experiences. Juggling work and family roles is itself stressful, and has severe psychological and physical effects (Greenhaus \& Parasuraman 1987, Frone et al. 1992). Yet it is extremely rare to see this issue highlighted in the increasing literature on stress amongst nurses.

This omission is particularly striking given the concerns about the impact of stress on nurses' well-being. This paper therefore describes some of the issues facing community mental health nurses (CMHNs) in the United Kingdom (UK) as they attempt to reconcile the roles of nurse and family member. Community mental health nurses present an interesting case because they work outside the institutions and workplaces which provide formal and informal support for working role identities to hospital-based staff. Furthermore, their frequent involvement in services which extend beyond normal business hours makes it difficult neatly to separate work 
and family time. This placed some peculiar pressures on participants in the present study, which has implications for the situation of community nursing staff in general. Moreover, our participants were facing a recent expansion in their out-of-hours responsibilities, involving emergency on-call time, following changes in their employment contracts. They also faced specific difficulties surrounding the care of people with severe and enduring mental disorders (Edwards et al. 2000).

\section{Making sense of roles - stasis, change and multiple responsibilities}

In order to make sense of the situation of community mental health nurses, it is necessary to consider what the concept of 'role' means. This idea has been widely used in the social sciences to illuminate work and family identities, being popularized especially by Talcott Parsons (1951). From the outset, theorists believed that playing roles might prove difficult if a person's role system contained simultaneous contradictory demands (Goode 1960).

In health care, early studies revealed that the roles of nurses were often ambiguous (Argyris 1955, Burling et al. 1956). Far from being a scripted performance, roles in health care were often more like cues for creative improvisation. The complexity has been compounded by extensive changes in policy and working practices (Walker et al. 2000). Therefore, the idea of nurses having a readily defined role is problematic for a number of reasons.

Firstly, there is a risk of exaggerating the unity and stasis of a nursing identity. In the UK educational initiatives in nursing, such as the development of large scale degree-level education, have changed the nature of the nursing role and affected nurses' sense of identity (Taylor et al. 2001). Moreover, the development of increasingly specialized, clinically autonomous and technically trained nursing roles is introducing even more uncertainty into what it means to be a nurse (Taylor et al. 1999, Ashworth et al. 2001, Gibson \& Bamford 2001). The nurse role cannot be taken for granted, but is continually being re-developed and re-evaluated. By contrast, many traditional concepts of occupational roles emphasize an initial period of socialization or 'role taking' followed by a period of stasis and well-rehearsed enactment through the working life (Mead 1934, Merton et al. 1957).

Secondly, the concept of role makes it difficult to grasp the idea of change. The effect of training, transition from student to qualified practitioner and changes in policy have been discussed, but the idea of ongoing change as a dynamic process is poorly understood. 
Whereas there is acknowledgement, mostly outside the literature on nursing, of the possible conflict or strain between work and home roles, the possibility that this conflict may provide a synergistic or dynamic impetus for shifts in career path, attitude to work or sense of self is underdeveloped.

The identities which practitioners have as family members or professionals may mutually affect one another. What Broadhead (1983) said nearly 20 years ago is still true today - there have been few attempts by researchers to analyse the meaning of a person's other identities for their identity as a health professional. There has also been a lack of discussion of how changes in one identity bring about changes in others. Research into these issues would provide some insight into the way individuals integrate one role identity with another. Although Broadhead dealt with medical students in his original study, the findings might be applicable to community mental health nurses, who also face the task of constructing a sense of self out of the multiple role socialization experiences they have as health professionals and as members of family and friendship structures.

The theoretical developments on this paper will be twofold. First, the notion of nurses' roles will be developed, showing how they might be best conceived as an interlocking dynamic system with other roles in the actors' lives, and how the notion of stress in nursing might be broadened to include the negative effects of these competing roles. Second, there will be an attempt to conceptualize change in role systems and in participants' lives.

Although the difficulties of discharging one's duties as a nurse or as a family member may be relatively long-term, moments of change are often sudden and unexpected. Analysing the process of change in the working lives of nurses will draw on the concept of 'punctuated equilibria'. This was originally proposed in evolutionary biology to describe how periods of stasis were 'punctuated' by moments of relatively rapid evolutionary change (Etheridge \& Gould 1972, Gould 1992). The concept may be used to illuminate the lives of nurses working in community mental health where their roles and, more importantly, their orientation to them may be suddenly revised as a result of life events and organizational changes. These changes may involve their feelings about their work, their sense of identity as family members or their working life as professionals. The idea of punctuated equilibria does not command the assent of all scholars of evolution, nor is it applicable to all processes of evolutionary change; however, it is a useful device through which to frame discussion of change in complex 
systems.

Despite there being few attempts to study nurses' multiple roles, the notion of roles itself has found its way into the discourse of those who study the health care professions. To speak of a nurse's 'role' is a convenient shorthand which encompasses aspects of education, specialism, workplace, working practice and responsibilities. For example, the social microstructure of the hospital helped to create what Stein called the 'doctor-nurse game' (Stein 1967, Stein et al. 1990). However, roles can have parallels with broader social structures and processes too. Valentine (1996) draws parallels between gender inequality in society at large and the difficulties that nurses, in a traditionally feminized profession, have had in acquiring status for their professional identity.

\section{Coping at work and home: spillover and contagion}

Role strain, according to Stanfield (1996), has three dimensions: role strain at home (intrarole), role strain at work (intrarole), and role strain because of the competing demands of home and work (inter-role). Researchers have noted the significance of inter-role tension between occupational and family roles, especially if stress spills over from one domain to another (Bolger et al. 1989, Crouter et al. 1989, Hughes et al. 1992). In addition, Galambos and Walters (1992) found that several aspects of women's work, such as work overloads, low rewards and low work status, were associated with higher stress levels (Giakanos 2000, Siann et al. 2000). However, although the majority of nurses are women and mothers (Cyr 1992), the dynamic strain between fulfilling family and work obligations in community mental health workers has not been studied.

According to Hopkinson et al. (1998), work stressors can result from the way an organization is structured, the manner in which it interacts with the world around it, the role of the individual within it, and the characteristics of the job and relationships with others in the organization. As Maslach et al. (2000) contend, chronic stress at work may lead to 'burnout', a syndrome characterized by exhaustion, cynicism and a sense of inefficacy. Although some studies have focused on the supportive aspects of family and organizations (Ray \& Miller 1994), strain caused by fulfilling both family and work demands has not been thoroughly investigated (Kopelman et al. 1983, Burke 1988, Shiu 1998, Kirkcaldy \& Martin 2000). The stress from competing work and family obligations in nursing is perhaps exacerbated by the similarity of the caring work involved in these roles. Smith (1992) describes care as 'emotional labour', 
after Hochschild (1983), and argues that the demands of emotional work with people who are ill and their families are severe, but are not easily recognized or valued. This is particularly the case in work with clients in their own homes, where close involvement between nurse and client and the isolation of the nurse can contribute to stress (Hayter 1999).

Parallels between work and home roles for many nurses are thrown into even sharper focus when gender dimensions are considered. Stanfield (1985) notes that in studies of other occupations, most role strain research assumes that women are the ones with multiple roles and are therefore most affected, juggling the demands of work and family. Thus, social scientists have conformed to prevailing social norms in viewing combined commitments to family and work as difficult for women (Pleck 1997).

There are, however, some exceptions to the general tendency to ignore the issue of stress due to role conflict in health personnel. For example, loss of time with family and friends was a stressor for nurses undertaking further study in addition to their work duties (Cox 1995). Shiu (1999) noted that such nurses face role strain, especially if they have children. In addition, Putska (1995) identified concerns about family members' health as a source of stress for nurses working for the United States Navy. These studies, however, have focused on the stress faced by nurses during an unusual event, such as family illness or further education. However, to make sense of the role of stress at work, it is necessary to consider the relationship between home and work in order to gain fresh insights into how nurses see stress as arising, and to offer new ways of conceptualizing, studying and ameliorating stress in nursing.

\title{
The study
}

\begin{abstract}
Aims
The study aimed to explore the hitherto neglected area of conflict between work and home roles amongst community mental health nurses, in order to characterize the situation they face and to develop concepts with which the field could be explored further. In line with the grounded theory approach (Strauss \& Corbin 1998) specific hypotheses were avoided at the outset, but as data collection progressed this focus on work-home conflict became increasingly clear. Thus, it was possible to fulfill a secondary aim, namely to explore more fully participants' accounts of the process of change in their working and home lives.
\end{abstract}




\section{Research approach}

In order to explore the interrelationship between work and home life we adopted a qualitative approach drawing on work on personal narratives and interpretive biography (Denzin 1989, Chamberlayne et al. 2000), as well as the related grounded theory method (Glaser \& Strauss 1967, Strauss \& Corbin 1998). Both these approaches emphasize the interrelatedness of data collection, on-going refinement of the research questions and theory building.

\section{Sample}

The participants consisted of 20 community mental health nurses working in the UK Midlands in an area which comprised both a new town and a traditional market town. Fifteen of the participants predominantly covered the market town and five the new town. In addition to their nursing duties four had management responsibilities, although all retained some caseload and patient contact. Seventeen were female and three were male. Despite having worked in the community for at least a year, with experience in this field ranging from 2 to 15 years, many (18) had backgrounds in hospital care and had received very little training to ease their transition from hospital to community.

\section{Interviews}

Interviews were conducted with a deliberately open structure to allow participants an opportunity to foreground issues which they felt were important. The method was inductive (Morse 1994) in that it was intended to prioritize participants' accounts and research insights gained from these in the analysis. The procedure was inductive on two levels. First, the aim to allow participants to construct their own accounts of their working lives led to identification of a pervasive concern with the relationship between work and home life. This provided a platform for further probing in subsequent questions. Second, emerging concern with the roles of, say, parenthood and nursing was accepted primarily in its own terms and not immediately repackaged as a manifestation of 'role conflict' in the traditional sense. In line with the grounded theory approach, the account presented here shows how the narratives from community mental health nurses go beyond and are richer than those hitherto present in the literature. 
The focus on possible tensions between home life and working life emerged partly from the topics raised by the participants. Thus, as the research developed, a greater focus on the possible conflict between home and working life was encouraged by the interviewer (PM). Whether or not participants' narratives were literally accurate, for example, when they talked about the connection between stress and illness, is not the point at issue. With interview data of this kind 'only the representations of experience can be captured' (Denzin 1989, p. 68). However, their importance lies in the role of the narrative in structuring experience and rendering an intelligible account of it to the reader or hearer.

\section{Ethical considerations}

Participants were briefed about the study and informed of their right to withdraw their participation or data at any time. In line with local ethics committee recommendations, they were advised of the confidentiality and anonymity of their responses and availability of support if the interview were to prove stressful. Whilst the details of participants' lives are reported as they were given, every effort was made to exclude details which would enable them to be identified.

\section{Data analysis}

The analysis process began with an initial intuition that there were important issues at stake in

the tension between home and working life. Recordings from the interviews were transcribed, inspected and searched electronically for occasions where issues relating to conflict between work and home life were prominent. Agreement was reached on the features which provided evidence of participants attempting to reconcile work and family commitments or highlighting conflict between them. The presentation of results here follows a series of themes, which, in line with grounded theory, first emerged as 'open codes', taking the form of intuitive guesses used to 'crack the data open'. They were subsequently developed and elaborated so as to resemble Strauss and Corbin's notion of 'axial codes'. At the core of this analysis, the overriding category to which the others are related is the notion of conflict between work and home. 


\section{Findings}

The presentation of findings is organized in terms of two major themes, namely: (1) The active negotiation of equilibrium between work and home and (2) The punctuations in that equilibrium and how they come about. Table 1 shows the relationship of these two themes to the categories identified in the interviews which will be elaborated upon later, and serves to emphasize that the equilibrium is dynamic and susceptible to sudden change.

Table 1 The active negotiation of equilibrium between home and work, and the creation of pressure for change leading to punctuations in the participants' life worlds

\begin{tabular}{|c|c|}
\hline Themes in the analysis & Codes and categories identified in the data. \\
\hline \multirow[t]{4}{*}{$\begin{array}{l}\text { 1) Active negotiation of equilibrium - competing } \\
\text { roles at work and home interact to create a } \\
\text { dynamic system. }\end{array}$} & $\begin{array}{l}\text { i) Conflict between work and home: Spillover and } \\
\text { contagion between roles. This issue forms the } \\
\text { foundation for the other codes and therefore } \\
\text { represents a core category. }\end{array}$ \\
\hline & $\begin{array}{l}\text { ii) Active coping to achieve a dynamic equilibrium } \\
\text { jointly organised through social support } \\
\text { networks. }\end{array}$ \\
\hline & $\begin{array}{l}\text { iii) Frenetic families - family life as a source of } \\
\text { perturbation in the participants' role system. }\end{array}$ \\
\hline & iv) Role conflict creates pressure for change. \\
\hline \multicolumn{2}{|c|}{ This equilibrium is dynamic and may therefore change suddenly. } \\
\hline \multirow[t]{2}{*}{$\begin{array}{l}\text { 2) 'Punctuated equilibria' Transitions of meaning, } \\
\text { transformations of living. }\end{array}$} & $\begin{array}{l}\text { i) Going off sick - the co-construction of } \\
\text { stress-related illness. Participants and their } \\
\text { doctors construct a reason for a break. }\end{array}$ \\
\hline & $\begin{array}{l}\text { ii) Emotion and change: Anger and the } \\
\text { punctuation of equilibrium - feeling angry with } \\
\text { the work situation as an incentive to introduce } \\
\text { some changes. }\end{array}$ \\
\hline
\end{tabular}

The active negotiation of equilibrium: constructing a life from the competing roles at work and at home

\section{Conflict between work and home - spillover and contagion}

The competing demands of home and work leave health professionals with the task of actively having to manage the boundaries and the conflict between the two. The first major category derived from the data, which forms a core category to which the other issues relate, concerns 
the ideas of 'spillover' and 'contagion'. This notion aligns participants closely with ideas about role conflict-related stress in the literature. For example, as one participant formulated the dilemma:

I think it's very difficult to work with people and not have a spillover. I mean if you're working with people who are depressed or suicidal... you often take that home with you and I think you have to be very aware yourself. For me it's team support. I mean....we have to look after our own mental health [otherwise]...we can't look after other people's.

Thus, participants echoed the findings of others (Ray \& Miller 1994) who have found a positive correlation between home and work stress and burnout in nurses. There is growing evidence that mental health professionals have particular vulnerability to stress (Rabin et al. 1999), and this was amply reflected in the corpus of material in the present study. For example:

...looking around me here I know now of four nurses who are off because of stress-related problems.

As with the comments above, Moore and Cooper (1996) found that the overriding common factors that lead to stress and burnout in nurses are the constant dealing with the emotional pain of others, inability to draw demarcation lines in their professional interactions, and nonreciprocated attentiveness to patients' problems and needs:

We do work in a certain flexible way in this team. Again I think it's always kind of been on an ad hoc basis, so it hasn't been, it's not formal. It tends to be informal. I think in mental health it's not clear-cut. You don't kind of leave your job behind. I think that's the type of job that it is, because you're dealing with people on a daily basis. Often they may need something on a Friday...but I think you may well go home and think about it over the weekend. You don't leave it behind. You take things home with you.

Conversely, some participants maintained their equilibrium by forcing a distinction between work demands and personal demands, so as to limit the extent to which their professional role could invade their lives:

There is an expectation that we will provide, but there are only so many hours in the day. I learnt a lesson years ago...from personal experience not to put in so many hours for my own sanity.

Recent research on the issue of work-family conflict has acknowledged that the relationship between work and family is bi-directional, such that the two spheres can have a reciprocal effect on each other. In studies of both nurses and other professions, work stress interfering with family life has been related to psychological and social problems for the individual (Broadbridge et al. 2000, Burke 1988). Bacharach et al. (1991) similarly found that work 
interference with family was related to burnout and lower job satisfaction for samples of both nurses and engineers. Thomas and Gangster (1995) have reported that work interfering with family is negatively related to job satisfaction and positively related to depression and health complaints among health care personnel.

The present study thus confirms that nurses must continually juggle a multitude of responsibilities demanded by their various roles. A wealth of studies has highlighted the adverse impact of occupational stress on health and life expectancy (Fletcher 1991). Professionals at the heart of care, such as community mental health workers, have been shown to experience particularly high levels of stress (Handy 1991, Carson et al. 1995). Most existing attempts to address stress amongst nurses have focused on features of the work itself. Insight from the present study, supported by literature on occupational stress in other professions, reveals that it is not the job per se, but the inter-role conflict between home and work that is crucial in producing a sense of stress. Whilst there are only a small selection of participants in the present study, the recognition of this reciprocal relationship between work and family must surely be a step forward for scholars of stress in nurses, and for the study of stress in community mental health nurses in particular.

\section{Active coping and dynamic equilibrium}

Participants were encouraged to develop their own narratives and the research focus was progressively attuned to their concerns, in line with recommendations from Strauss and Corbin (1998) and Chamberlayne et al. (2000). This allowed further codes to be identified, yielding insights into the nature of the stress that emerged from the work-home conflict. Participants were not passive recipients of the stress, but rather they were active in trying to make sense of it, often using conceptual tools very similar to those of the social scientist:

I think it's harder for female CPNs [community psychiatric nurses]. Again, often it may be a generalisation. It's not the case in all cases. Certainly most men go home to a wife who's organised the kids or organised school or organised the school run or organised the holidays or whatever. So I think female CPNs find it harder. The kind of stress builds up over a period of time...every 10-12 weeks you just have to have a break. You have to get away from it [the stress] because it's around, and because it's around all the time - it never really goes away.

Paid employment is a part of the lives of a large and increasing proportion of women; yet, until 
recently, relatively little was known about how work conditions affect their psychological functioning (Miller et al. 1979). The past two decades have seen rapid developments in research on how women's paid employment affects their family relations (Spitze 1998). Employment decreases women's level of depression only if they experience high levels of job satisfaction (Kessler \& McRae 1982). If the satisfactions are eclipsed by stress, this may have an adverse effect on overall wellbeing and family life.

A further feature of the equilibrium maintained in some participants' lives was that it was a joint activity such that their social support networks were enlisted to sustain continued viability at home and at work. Partners were an especially valuable resource in the joint maintenance of viability:

I just go bananas here, I really have. It's terrible. And...it's just impossible, and the housework is terrible and my husband is very good. He does the ironing on a Saturday morning once he's got Luke to football. The house is a mess, the back's going, the stress levels are hugely high and I just cope by my yelling and screaming...very little time...that isn't involved with other work or music lessons.

Adults typically occupy multiple roles such as spouse, parent, or worker, and the literature attests to the fact that there are intimate connections between adults' role related experiences and their psychological well-being (Barnett \& Baruch 1985, Baruch \& Barnett 1987). Making sense of experiences such as those outlined by the participant above might involve several possibilities. O'Neil and Greenberger (1994) note that the responsibilities arising within each sphere of activity may lead to feelings of conflict between and among roles. In addition, Marks (1977) has argued that if an individual experiences role strain or role conflict, they do so because they are under-or over-committed to one role relative to the other, and not as a direct result of an actual excess of role demands. Conflict between the roles of parent and professional is most likely because, as O'Neil and Greenberger (1994) argue, people who occupy both these roles view them as central to their identity. One's role may be related to the sense of identity through a reciprocal process, in which commitment to the role strengthens feelings of identity, and identity in turn strengthens or increases role relevant actions, relationships and organizational ties (Burke \& Reitzes 1991).

\section{Frenetic families}

The demands of family life were often described as being severe, meriting a code in its own 
right. This, however, must be seen in relation to work-family conflict. Bolger et al. (1989) and Baruch et al. (1987) note that large numbers of married couples have adopted lifestyles in which both members have jobs outside the home and share parenting responsibilities. A major explanation for how the combination of work and family roles generates stress is that there is a contagion of stressful experiences between the two role domains (Piotrkowski 1979).

Therefore, according to Bolger et al. (1989), overloads in one role domain lead to overloads in the other. Again, this is visible in the previous quote, where work demands meant that the participant was experiencing distress about the state of her home. The joint involvement of her partner in some housework and childcare might suffice to maintain the situation, but was not sufficient to yield satisfaction. As many scholars have noted, women who carry dual responsibilities for home and job may become fatigued by the effort needed to fulfill both sets of role requirements (Miller et al. 1979). The effort needed to provide anything beyond a very basic range of parenting tasks, such as support for children's sporting, cultural or social activities, yields a particularly frenetic lifestyle:

But the other side of my job, you see, I spend 31 hours a week on children's music [l: yes] and they're 7 and $8 \ldots$... and Em[ma] does violin, she's 7, and she does it so well that her teacher wants her to audition...which is great, but it means that we have to get up at half past six in the morning. Yes, and [my son] he's 8 and does cello and piano. He's a good pianist and cello is his second instrument, so he does half an hour of whatever instrument he has chosen. Then I walk him to school with her on the bike, then get the car and drive to work.

The intimate daily interactions of family life are affected by the economic activities of family members. However, the connections between family life and employment are complex (Menaghan \& Parcel 1990), requiring meticulous planning of daily routine, the emotional tone of family interactions and the educational, cultural and career opportunities afforded to other family members - in this case the participant's dedication to developing her children's musical capacities.

\section{Role conflict as a pressure for change}

Epstein (1971) and Weingarten (1978) conclude that if the demands and pressures of a person's commitments cannot all be met, then role strain will result from the guilt. According to St John-Parsons (1978) the wife/mother primarily bears the emotional strain. In 1978 as now, it is often the mother who has to get the children ready for school or day care and cares for them 
during the school holidays or if they are ill. Barling and MacEwen (1991) found that mothers' attitudes towards outside employment affect their mood, something which in turn affects their parenting behaviour, as reflected in the present study:

...she's my child. l'll take my child to school half an hour before any other child gets to school because I have to come to work, and she has to go [to] after school club because I can't pick her up at 3ÆE20. These sorts of things. So I probably resent her a lot more than I used to...so it's quite interesting to have gone through $4-5$ years of battling my way to this place or whatever, and being angry with [my child] for getting chicken pox and stuff like that, and thinking that they would think badly of me. and I take what I feel now and the reaction isn't any different. You need to...make sure that people know that you've got children. I have to come to work at 7 o'clock in the morning and the needs of the organization are such that they won't need me at 7 o'clock, but they might do.

In this quote, feeling angry with a child for being ill is described as an emotional consequence of trying to juggle work and home. Participants echoed the situation detected over 20 years ago by Bryson et al. (1978), who argued that women in dual career families bear a disproportionate share of the burden for child care and that in these families traditional sex roles still seem to be the basis for allocating child care responsibilities:

I'd worked full-time all that time. So much as I wanted her, I was sort of in the throes of the job and everything. I took 5 months off before I came back to work and my daughter went straight into day-care, and actually...I feel galled about this now, but then that didn't actually bother me at all, that I wasn't around as a mother when she was 7 or 8 months, 10 or 11 months old.

In this quote it is possible to see additional complexities emerging when people describe their experiences of the intersection between home and work roles - that is, the effects may not be immediately apparent but may emerge after the individual has had time to reflect on the strategies they adopted at the time. The pressure or desire for change was also detected in other interviews, for example, in statements such as:

I just feel stressed all the time. I mean, my ex-husband used to say, 'Why are you doing this to yourself?'

In addition, there were more nuanced accounts, where the state of working life itself was identified as more directly responsible for the difficulties:

I suppose it gets to a point where you start thinking what's the point of coming in, I mean, what good are we doing, when, you know, I spend all my time at it. When I think of my family, I mean, they'd actually appreciate seeing more of me, I'm sure they would. 
Thus, even when there are periods of relative equilibrium, the seeds may be germinating for a transformation. Participants in the previous three quotations did not always regard their maintenance of the status quo with satisfaction or equanimity. These undercurrents of dissatisfaction, combined with the possibility of change inherent in many family situations, help to create pressures for change which, when it takes place, may be sudden and involve a reconfiguration of world view. These transitions - moments of change or 'punctuations' - will be described in the next section as the counterpoint to periods of stasis.

\section{Punctuated equilibria: transitions of meaning, transformations of living}

Going off sick - the co-construction of stress related illness

The increasing body of research on the relationship between work and family life has suggested interconnecting influences between the two spheres (Cooper 1988, Carlson \& Perrewe 1999). The experience of stress at work has become part of the currency of everyday talk about work (Hopkinson et al. 1998). Thus, workers come to make sense of their personal difficulties as being the result of the impact of a stressor upon them (Parry Jones et al. 1998). For example, in the following quote we see a participant formulating the relationship between the lack of support at work and her lack of personal resources available for other family members:

I ended up going off sick because I think the stress is not recognised. It's not recognised by managers. They don't see that you're in really stressful situations and certainly [l] am aware that there are CPNs around who do opt out, and they opt out of doing anything other than just managing their caseload. and I can see why they do it, because to actually take on extra stuff isn't recognised, and nobody recognises it and nobody ever comes and says, 'You did a really good job there...well done' or...l've done this degree off my own back. Nobody will come and say, 'Well done, you've got a degree, you've done it all, you've managed work.' and nobody will say that. and nobody can see the effect that it's certainly had on my family, which it has, there's no doubt about that. Very stressful. and they sometimes had to take a second seat because...when you've got assignments and you've got dates to meet, then they go out of the window.

This participant identified lack of support from senior colleagues at work as being significant in 'going off sick', which is in keeping with the results of other studies. This, then, is what is meant by a punctuation of the equilibrium, where difficulties of work and home appear to 
precipitate a crisis in the individual's wellbeing. Whereas the benefits of social support in stress have been well documented, the support received by participants sometimes took unexpected forms. Supportive social relationships may provide the opportunity to change one's situation. Participants described fellow healthcare workers, such as General Practitioners (GPs), collaborating with them and helping to reshape their difficulties into a form which would be acceptable to employing organizations:

You know, when I went to see my GP, like when I lost babies, or I had to go onto sick [sick pay] just after my marriage broke up, she asked, 'What do you want me to write?'. So when my marriage broke up it was called 'gastritis', and the first pregnancy that I lost was called 'postoperative procedures'...GPs here are not actively supported by the local hospital...so even my colleagues I know are on sick leave with professional stress, the GPs are reacting in much the same way and are willing to provide you with a certificate not to come [to work]. I mean, it's quite fascinating because they recognise the stresses that people are being put under. I know that if I went to my GP she would say to me, 'Do you want a break? I'll give you a break'. So they know the reputation of the health service.

In this quote there is evidence that the stress, which is related to the reciprocal impact of personal difficulties and work demands, and its consequences are 'co-constructed'. The formulation of occupational stress and its sequelae, such as physical illness, is a joint effort on the part of the participant and her GP. Again, rather than a static individualistic notion of stress, the participant is accounting for it as a dynamic process whereby it is transacted and negotiated in joint social action between two or more actors. Thus, the 'punctuations', rather like the periods of equilibrium identified in the previous section, are mutually produced by people acting jointly.

\section{Emotion and change: anger and the punctuation of equilibrium}

In general, the literature has tended to conceptualize contemporary role conflict and role strain as being to do with the fact that today's workforce consists largely of employees with high family demands. It has also called attention to the way in which combining occupational and family roles is a source of ongoing and relatively constant stress for workers and their families (Hughes et al. 1992). However, it was clear from many of our interviews that difficulties around the relationship between home and work were precipitated by a critical incident:

... like my dad died last year and that's the first close bereavement that l've ever experienced...they gave me time off but I came back to work and I worked two weeks and I 
was truly offended by the lack of compassion that I received...and to the point that I got very angry with people. I got so angry that I wouldn't speak to anybody, because I couldn't believe that my boss couldn't ring me up and, 'Say how's things?'. You know, 'Don't worry about your stuff' or anything...I was so steamingly angry with everybody in this place for being so uncaring about my dad, and what I got back was, 'Well, you know, we can't care about everybody's dad'. Well, you bloody well should. You should do. Even if it's just to ring up and ask how they are.

This participant's account embodies more than a sense of ongoing role strain: it shows how the realization that the situation is unacceptable comes as a result of a critical incident. This theme of sudden, emotional realization was common to a number of accounts and, according to Denzin (1989), is a powerfully entrenched part of the autobiographical storytelling form, where lives are turned around by significant events. Denzin (1989) calls these moments 'epiphanies' - 'interactional moments and experiences which leave marks on people's lives' ( $p$. 70).

The sequence of codes we have described here show how relatively stable periods of coping can be disrupted by sudden 'punctuations' as critical incidents emerge and their meaning is assimilated by the participant. The sense from these narratives of change is of events suddenly outstripping coping resources and creating moments of rapid change. The idea of punctuated equilibria was arrived at inductively, as a result of attempting to code the rich diversity of the data and explore the relations between the different aspects and the overriding issue of home-work conflict with its associated spillover and contagion identified in the first code. The term also highlights how the periods of equilibrium often involve maintenance of the status quo despite changes in work or life circumstances, such as having a baby, whereas the punctuations may come later as a result of a subjective re-evaluation of one's life or the cumulative experience of stress.

\section{Conclusion: roles, responsibilities and active negotiation of the home-work interface}

This paper has addressed the question of stress amongst community mental health nurses from the point of view of their own subjective accounts of their jobs, and has disclosed several important implications for the study of stress in nurses and for the development of theories about roles, stress and professional identity. Although the study is small-scale and only limited claims can be made concerning its generalizability, the data may be used to emphasize a 
number of possible theoretical and empirical developments which would enrich the study of these issues.

First, the argument has been advanced that stress intrinsic to the job of CMHNs is only one facet of participants' experience, and it is important to consider the complexity of their interconnected role systems and obligations, values and ideals in order to grasp the effect it has on individual nurses. The issue of stress arising from the conflict between home and work roles has been explored more fully in studies of other occupations, and the implications of these findings have yet to be assimilated in studies of nursing. Therefore, despite the tentative nature of the findings, we argue that they support the contention that stress research in nursing should embrace the issue of work-home role conflict.

Secondly, the notions of role derived from functionalist sociology have some major limitations. The overwhelming sense they give is of actors as relatively passive recipients of the socialization process, as they are taught the major components of their status and role. In this classical formulation, they are not active negotiators of the role's demands (Ritzer 1996). However, with nursing there are longstanding concerns that the job does not involve a clearly prescribed set of practices, and that nurses have to improvise their performance on the basis of rather ambiguous cues (Argyris 1955). Certainly, this was echoed in the data presented here, where the role and distinction between the nursing role and home life were described as not being clear-cut. Equally, family life is a constantly changing experience as participants, their children and partners undergo their own life changes, and patterns of education, interests, health and illness in the family have a perpetually changing impact on participants' working lives. In the light of this, it is instructive how participants described themselves as active in reformulating, moderating and transforming the demands of their roles. Their meticulous planning and organization of work and family life, sometimes down to the precise specification of their routines, attests to the creative strategies they used to manage their lives. The meaning of roles is not static, but health care staff are active in constructing the meaning and purpose of their roles in situ as their professional and domestic lives unfold.

Thirdly, the possibility that the demands from work and home life might not simply yield an ongoing experience of stress in a simple dose-response fashion has been raised. Although these demands may be important facets of their experience, the balance of work and family which participants accomplish may appear to be relatively stable. However, there may be 
transformational moments in this equilibrium. These moments, which Denzin (1989) describes as 'epiphanies', can be seen in participants' accounts, accompanying stories of visits to the doctor, having children, and family bereavements. This picture of periods of relative constancy interspersed by periods of rapid re-evaluation is reminiscent of the punctuated equilibria described by Gould (1992). In the present study these were sometimes enacted jointly between participants and their GPs, and often involved emotional transformations. To examine people's attitudes to their jobs or their experience of stress at any one time is to see only a snapshot. However, the present study hints that in order to grasp the full picture a sense of how change may suddenly occur in participants' lives is required. We suggest that researchers should be attentive not only to the ongoing experience of stress, but also to the possibility that there may be 'punctuations', 'epiphanies' or sudden changes amid the periods of equilibrium.

We recommend that researchers consider a new way of thinking about community mental health nurses, and perhaps nurses in general, that fully grasps the way in which their lives are an interlocking complex of roles at home and at work. Their lives, like those of participants in this study, may be multifaceted. Seeing their accomplishments and their distress in terms of how roles at home and work may conflict will allow researchers and policymakers to grasp the complexity of occupational stress and its causes. More generally, this paper underscores the importance of participants' own narratives of the experience of stress. Far from being one-dimensional, the experience of stress is intimately bound up with the collaborative human process of making sense of the subjective world, and may result in sudden shifts of perspective on the part of those who suffer from it. It is here that researchers should look for fresh insights into the everyday activity of surmounting stress. If this complexity can be grasped, it will highlight how managers, policymakers and community mental health workers can safeguard their professional effectiveness without the danger of family life 'going out the window'.

\section{References}

Argyris C. (1955) Human Relations in a Hospital. Yale University Press, New Haven, CT, USA. Ashworth P.D., Gerrish K. \& McManus P. (2001) Whither nursing? Discourses underlying the attribution of Master's level performance in nursing. Journal of Advanced Nursing 34, 621-628. Bacharach S.B., Bamberger P. \& Conley S. (1991) Work-home conflict among nurses and engineers: mediating the impact of role stress on burnout and satisfaction at work. Journal of Organizational Behaviour 12, 39-53. 
Barling J. \& MacEwen K.E. (1991) Employed mothers' experiences and children's behaviour. Journal of Marriage and the Family 53, 635-644.

Barnett R.C. \& Baruch G.K. (1985) Women's involvement in multiple roles and psychological distress. Journal of Personality and Social Psychology 49, 135-145.

Baruch G.K. \& Barnett R.C. (eds) (1987) Role Quality and Psychological Well-being. Yale University Press, New Haven, CT, USA.

Baruch G.R., Biener L. \& Barnett R.C. (1987) Women and gender in research on work and family stress. American Psychologist 12, 130-136.

Bolger N., DeLonghis A., Kessler R.C. \& Wethington E. (1989) The contagion of stress across multiple roles. Journal of Marriage and the Family 51, 175-183.

Broadbridge A., Swanson V. \& Taylor C. (2000) Retail change: effects on employees' job demands and home life. International Review of Retail, Distribution and Consumer Research 10, 417-432.

Broadhead R.S. (1983) The Private Lives and Professional Identities of Medical Students. Transaction Books, New Brunswick, NJ, USA.

Bryson R., Bryson J. \& Johnson M. (1978) Family size, satisfaction and productivity in dual career couples. Psychology of Women Quarterly 3, 67-77.

Burke R.J. (1988) Some antecedents and consequences of work-family conflict. Journal of Social Behaviour and Personality 3, 287-302.

Burke P.J. \& Reitzes D.C. (1991) An identity theory approach to commitment. Social Psychology Quarterly 54, 239-251.

Burling T., Lentz E. \& Wilson R.N. (1956) The Give and Take in Hospitals, Putnam, New York, USA.

Carlson D.S. \& Perrewe P.L. (1999) The role of social support in the stressor strain relationship: an examination of work-family conflict. Journal of Management 25, 513-540. Carson J., Bartlett H., Fagin L., Brown D. \& Leary J. (1995) Stress and the community psychiatric nurse. In Community Psychiatric Nursing: A Research Perspective, vol. 3. (Brooker C.W. ed.), Chapman \& Hall, London, pp. 148-173.

Chamberlayne P., Bornat J. \& Wengraf T. (2000) The Turn to Biographical Methods in Social Science. Routledge, London.

Cooper C.L. (ed.) (1988) Work Stress. Blackwell Science, Oxford.

Cox D.D. (1995) The Impact of Stress, Coping, Constructive Thinking and Hardiness on Health and Academic Performance of Female Registered Nurse Students Pursuing a Baccalaureate Degree in Nursing, PhD Thesis, University of Pittsburgh, Pittsburgh. 
Crouter A.C., Perry-Jenkins M., Houston T.L. \& Crawford D.W. (1989) The influence of work-induced psychological states on behaviour at home. Basic and Applied Social Psychology 10, 273-292.

Cyr J.P. (1992) Males in nursing. Nursing Management 23, 47-56.

Denzin N. (1989) Interpretive Biography, Sage University Paper Series on Qualitative Research Methods, vol. 17. Sage Publications Inc, Beverley Hills, CA, USA.

Edwards D., Burnard P., Coyle D., Fothergill A. \& Hannigan B. (2000) Stress and burnout in community mental health nursing: a review of the literature. Journal of Psychiatric and Mental; Health Nursing 7, 7-14.

Epstein C.F. (1971) Law partners and marital partners: strains and solutions in the dual career family. Human Relations 24, 549-564.

Etheridge N. \& Gould S.J. (1972) Punctuated equilibria: an alternative to phyletic gradualism.

In Models in Paleobiology (Schopf T.J.M. ed.), Freeman, San Francisco, pp. 82-115.

Fletcher B.C. (1991) Work, Stress, Disease and Life Expectancy. John Wiley \& Sons Ltd, Chichester.

Frone M.R., Russell M. \& Cooper M.L. (1992) Antecedents and outcomes of work-family conflict: testing a model of the work- family interface. Journal of Applied Psychology 77, 65-78.

Galambos N. \& Walters B.J. (1992) Work hours, schedule inflexibility and stress in dual earner spouses. Canadian Journal of Behavioural Sciences 2, 290-302.

Giakanos I. (2000) Gender roles and coping with work stress. Sex Roles 42, 1059-1079. Gibson F. \& Bamford O. (2001) Focus group interviews to examine the role and development of the clinical nurse specialist. Journal of Nursing Management 9, 331-342.

Glaser B.G. \& Strauss A. (1967) The Discovery of Grounded Theory. Aldine Publishing Co, New York, USA.

Goode W.J. (1960) A theory of role strain. American Sociological Review 25, 483-496. Gould S.J. (1992) Punctuated equilibria in fact and theory. In The Dynamics of Evolution (Somit A. \& Peterson S.A. eds), Cornell University Press, Ithaca, NY, USA, pp. 54-84. Greenhaus J.H. \& Parasuraman S. (eds) (1987) Integrating Work and Family, Challenges and Choices for a Changing World. Quorum Books, Westport, CT, USA.

Handy J.A. (1991) The social context of occupational stress in the caring professions. Social Science and Medicine 32, 819-830.

Hayter M. (1999) Burnout and AIDS: care related factors in HIV community clinical nurse specialists in the North of England. Journal of Advanced Nursing 24, 984-993. 
Hochschild A. (1983) The Managed Heart: The Commercialisation of Human Feeling. University of California Press, Berkeley, CA, USA.

Hopkinson P.J., Carson J., Brown D., Fagin L., Bartlett H. \& Leary J. (1998) Occupational stress and community mental health nursing: what CPNs really said. Journal of Advanced Nursing 27, 707-712.

Hughes D., Galinsky E. \& Morris A. (1992) The effects of job characteristics on marital quality: specifying linkage mechanisms. Journal of Marriage and the Family 54, 31-42.

Kessler R.C. \& McRae J.A.J. (1982) The effects of wives' employment on the mental health of married men and women. America Sociological Review 47, 216-227.

Kirkcaldy B.D. \& Martin T. (2000) Job stress and satisfaction among nurses: individual differences. Stress Medicine 16, 77-89.

Kopelman R.E., Greenhaus J.H. \& Connolly T.F. (1983) A model of work, family, and inter-role conflict: a construct validation study. Organizational Behaviour and Human Performance 32, 198-215.

Marks S.R. (1977) Multiple roles and role strain: some notes on human energy, time, and commitment. American Sociological Review 42, 921-936.

Maslach C., Schaufeli W.B. \& Leitere M.P. (2000) Job Burnout. Annual Review of Psychology 52, 397-422.

Mead G.H. (1934) Mind, Self and Society. University of Chicago Press, Chicago.

Menaghan E.G. \& Parcel T.L. (1990) Parental employment and family life: research in the 1980s. Journal of Marriage and the Family 52, 1079-1098.

Merton R.K., Reader G.G. \& Kendall P.L. (eds) (1957) The Student-Physician: Introductory Studies in the Sociology of Medical Education. Harvard University Press, Cambridge, MA, USA.

Miller J., Schooler C., Kohn M.L. \& Miller K. (1979) Women and work: the psychological effects of occupational conditions. American Journal of Sociology 85, 66-94.

Moore K.A. \& Cooper C.L. (1996) Stress in mental health professionals: a theoretical overview. International Journal of Social Psychiatry 42, 82-89.

Morse J.M. (1994) Critical Issues in Qualitative Research Methods. Sage Publications Inc., Thousand Oaks, CA, USA.

O'Neil R. \& Greenberger E. (1994) Patterns of commitment to work and parenting: implications for role strain. Journal of Marriage and the Family 56, 101-118.

Parry Jones B., Grant G., McGrath M., Caldock K., Ramcharan P. \& Robinson C.A. (1998)

Stress and job satisfaction among social workers, community nurses and community 
psychiatric nurses: implications for the care management model. Health and Social Care in the Community 6, 271-285.

Parsons T. (1951) The Social System. Free Press, Glencoe IL, USA.

Piotrkowski C.S. (1979) Work and the Family System: A Naturalistic Study of Working-Class and Lower-Middle Class Families. Free Press, New York, USA.

Pleck R. (1997) The work family role system. Social Problems 24, 417-427.

Putska N.A. (1995) Quality of Life in Relation to Stressful Life Events: Daily Hassles and Coping Responses Among Midlife Female Navy Nurses, DNSc. Thesis. The Catholic University of America, Washington, DC.

Rabin S., Feldman D. \& Kaplan Z. (1999) Stress and intervention strategies in mental health professionals. British Journal of Medical Psychology 72, 159-169.

Ray E.B. \& Miller K.I. (1994) Social support, home/work stress, and burnout: who can help? Journal of Applied Behavioural Science 30, 357-373.

Ritzer G. (1996) Sociological Theory, 4th edn. McGraw-Hill International Editions, New York, USA.

Shiu A.T.Y. (1998) Work and family role juggling and mood states of Hong Kong health nurses with children. Journal of Advanced Nursing 28, 203-211.

Shiu A.T.Y. (1999) The part time student role, implications for the emotional experience of managing multiple roles amongst Hong Kong public health nurses. Nurse Education Today 19, 188-198.

Siann G., Riley S., Wilson F. \& Callaghan M. (2000) Gender at work and home in Britain. Journal of Applied Social Psychology 30, 2491-2512.

Smith P. (1992) The Emotional Labour of Nursing. Macmillan, London.

Spitze G. (1998) Women's employment and family relations: a review. Journal of Marriage and the Family 50, 595-618.

St John-Parsons D. (1978) Continuous dual-career families: a case study. Psychology of Women Quarterly 3, 30-42.

Stanfield J.B. (1985) Research on wife/mother role strain in dual-career families. American Journal of Economics and Sociology 44, 355-363.

Stanfield J.B. (1996) Married with Careers: Coping with Role Strain, Avebury, Aldershot.

Stein L.T. (1967) The doctor nurse game. Archives of General Psychiatry 16, 699-703.

Stein L.T., Watts D.T. \& Howell T. (1990) The doctor nurse game revisited. Nursing Outlook 38, 264-268.

Strauss A.L. \& Corbin J. (1998) Basics of Qualitative Research: Techniques and Procedures 
for Developing Grounded Theory, 2nd edn. Sage Publications Inc, Thousand Oaks, CA, USA. Taylor H.R., Westcott E. \& Bartlett H.P. (2001) Measuring the socialisation of graduate and diplomate nurses using the Corwin Role Orientation Scale. Journal of Advanced Nursing 33, 20-28.

Taylor S., White B. \& Muncer S. (1999) Nurses' cognitive structural models of work based stress. Journal of Advanced Nursing 29, 974-983.

Thomas L.T. \& Gangster D.C. (1995) Impact of family supportive work variables on work family-conflict and strain: a control perspective. Journal of Applied Psychology 80, 6-15. Valentine P.E.B. (1996) Nursing: a ghettoised profession relegated to women's sphere. International Journal of Nursing Studies 33, 98-106.

Walker L., Barker P. \& Pearson P. (2000) The required role of the psychiatric-mental health nurse in primary care: an augmented Delphi study. Nursing Inquiry 7, 91-102.

Weingarten K. (1978) The employment pattern of professional couples and their distribution of involvement in the family. Psychology of Women Quarterly 3, 43-52. 